This is an Accepted Manuscript of an article published by Taylor \& Francis Group in Historical Journal of Film, Radio and Television on 14 Jun 2019, available online: http://www.tandfonline.com/10.1080/01439685.2019.1628418

\title{
The Need for Speed? A Historical Analysis of The BBC's Post-War Broadcasting of Motorsport
}

\section{Richard Haynes (University of Stirling) and Timothy Robeers (University of Antwerp)}

\author{
Historical Journal of Film, Radio and Television
}

(Accepted for publication 8 April 2019)

Print ISSN: 0143-9685 Online ISSN: 1465-3451

\begin{abstract}
Although many media and cultural histories have looked at the emergence of particular popular sports, few have done so from a detailed perspective with respect to motorsport. Indeed, ever since its conceptualisation, motorsport has shared an intricate relationship with the media. However, despite advancements in camera and broadcasting equipment, significant technical and logistical difficulties to represent early motorsport as televisual, with a strong sense of 'realism', persevered. This article explores the emergence of motorsport on BBC television during the post-war period to determine if, and to what extent, early motorsport on television was (not) televised. To this end, a qualitative archival approach is used to examine a sample of archival and biographical media texts from the post-war period. Findings suggest the BBC experimented with the format of the hill climb, a motorsport series, by shaping it to fit the possibilities and requirements of television more appropriately. This resulted in the creation of the Television Trophy Trial, the adoption of scrambling and the rise of Rallycross. This means that the BBC was, in effect, not only using motorsport to its own benefit from the early 1950s onwards, but actively developing and representing motorsport as competitive and dramatic.
\end{abstract}

\section{Keywords}

Post-war years, motorsport, television broadcasting, representation, archival approach 


\section{Introduction}

This article traces the formative history of British television's coverage of motorsport from 1946 to 1970 . In doing so, it aims to fill a gap in academic media and sport histories of motorsport, which have largely focused on Formula 1 grand prix racing from the mid-1970's onward. Based on archival research in the BBC Written Archives Centre, interviews with broadcasters and biographical research, the article opens up a discussion on the early organizational, technical, spatial and temporal challenges faced by television in its attempt to bring coverage of motorsport on to the small screen.

As Britain's first public service broadcaster, the BBC experimented with, and effectively pioneered, broadcasting sport on television from 1936 onwards. ${ }^{1}$ In the first two decades of the BBC's Television Service, from 1936-to 1939, and 1946 in to the mid-1950's television grew in the shadow of its sister services in radio, often viewed as the "peep show boys at Alexandra Palace'. ${ }^{2}$ In spite of the fact BBC radio had built strong relationships with sport through the 1920's and 30's, television frequently faced stiffer opposition from sport administrators due to the fear that live moving images from sport would impact on attendances at spectator sports. ${ }^{3}$ However, when televised sport first began in the 1930's, the medium had a much more benign influence on sport. ${ }^{4}$ Sport governing bodies ruled, and certain sport administrators held the power in the relationship with the BBC. ${ }^{5}$ Many administrators were convinced by the argument put forward by the Association for the Protection of Copyright in Sport, that sport had a copyright in their performance much like musicians, which led to dispute and boycott from transmissions by some major sports. ${ }^{6}$

Television was also constrained by its technology. Pre-war outside broadcasts were initially constrained by the length of the cabling from Alexandra Palace to the cameras. Microwave links enabled the BBC to cover the (Oxford/ Cambridge) Boat Race for the first time in 1937, but the logistics of doing so were expensive for a new medium working on limited resources. ${ }^{7}$ As Garry Whannel has argued, televising sport, showing a sport as 'the real thing' 
or as it is being played, historically correlates to the level of technological capabilities of television broadcasting of each period, and as such, is dependent on the level of control that television exerts on both sport and the sporting environment. ${ }^{8}$ These processes echo the idea from critical television studies that suggest the medium both ingests from, and projects into, culture and society. ${ }^{9}$ Firstly, the BBC's approach to sport from early on was characterized by a desire for the cultural ingestion of sport - drawing the 'world of sport' towards itself to incorporate and transform sport for its own needs and ends. What is 'on' television, therefore, can be recognized as part of institutional structures, practices and relationships television develops with sport, which in time have changed and become increasingly intertwined and interdependent as sport has adapted itself to the needs of being televised. Secondly, the BBC also projected its images and commentaries into the culture of sport and beyond, permeating popular culture with its iconic moments and distinctive voices in order, consciously or not, to produce collective memories of sport which first and foremost are moments of television culture. For example, the BBC motor racing commentator Murray Walker became synonymous with Formula 1 from the 1970's onwards, in particular for what became known as his 'Murrayisms'. ${ }^{10}$ Through this ingestion and projection processes television has shaped its relationship with sport, influencing its social and cultural resonance.

A range of media and cultural histories have looked at the emergence of particular popular sports such as football, cricket, boxing and snooker on post-war television, but interestingly none have focused on motorsport. ${ }^{11}$ More general histories certainly include some information about early coverage of motorsport, but not in any extensive detail. ${ }^{12}$ This is perhaps surprising considering both the economic scale and cultural importance of motorsport, which in the case of Formula 1 is a global, high profile, media sport.

Nick Henry et al define motorsport as 'competitive racing by equivalent machines on an equivalent basis'. ${ }^{13}$ Although diverse in terms of both machines and competitive events, in the post-war period, the popularity of motorsport has largely been synonymous with Formula 1 
grand prix racing. Such narrow popular perceptions of Formula 1 as the 'jewel' or 'pinnacle of motor sport', elides Henry et al's broader definition indicating the generic nature of motorsport comprising both 'disciplines' (for example, open-wheel, sportscar, rally and others) and 'series' (for example, Formula 1, Formula 2, Formula 3, Formula E). ${ }^{14}$ Considering Formula 1 only gained consistent significance on British television from 1974 onwards with the symbiotic relationship between superstar names (James Hunt) and commercial sponsorship of cars, particularly by the tobacco companies (Marlboro) gaining regular television coverage on the BBC. ${ }^{15}$ Because of the lack of historic visibility on television before the mid-1970's, the period prior to this has largely been left aside by academic historians. On the other hand, and until recently, academic research on motorsport in general has long remained scarce and fragmented at best. ${ }^{16}$ Motorsport provides many mediatized global events which sustains a combined audience of over 1 billion people and generates a $£ 50$ billion plus annual industry turnover, but little is known of how the formative period of this relation began or developed over time. ${ }^{17}$

Adopting an archival approach, this article explores the emergence of motorsport series on BBC television, and subsequently ITV, during the immediate post-war period in order to determine the scale and nature of coverage of motorsport on British televised between the late1940's and 1970. In doing so, it provides a historical backdrop of the motorsport scene during this period and the first detailed understanding of the representation of motorsport on television and wider implications for the sport in popular culture. The article elaborates on the use of archives to inform the history of televised motorsport, exploring the empirical and theoretical challenges of writing such a history. We then analyse the evidence to suggest that in the formative history of motorsport on television there were early attempts to create competitive events which suited the needs of the cameras and service to viewers. The motivation for doing so largely came from constraints in technology and a desire to broaden the range of sports being broadcast. 


\section{Exploring the historiography of motorsport on television}

Television has transformed both the economics and cultural significance of sport contributing to a global media-sport nexus which for many people is their main point of contact with the world of sport. ${ }^{18}$ As Gary Crawford points out, television has become a major and global part of the way in which different sports represent themselves and continues to contribute to the popularity and growth of modern sports to the extent that, for a while now, 'sport is television sport'. ${ }^{19}$ Although we can recognize television has culturally transformed sport for its own ends, historical evidence of how the textual and narrative logic of television emerged and developed in the transformation of motorsport is thin on the ground. A major challenge of researching the historiography of television is the lack of survival of television broadcasts themselves, particularly from the first three decades of the medium. ${ }^{20}$ Little survives of early television coverage of motorsport, especially where it was live outside broadcast transmissions, and even where telerecordings or video recordings exist, access to such material for researchers is difficult to obtain due to copyright restrictions.

This study therefore focuses on the written record of programmes - through production notes, correspondence and associated material on broadcasts from the BBC's WAC - alongside the digital record of scheduled output from 1946 to 1970 stored within the BBC Genome website, produced from the BBC's in-house listing magazine The Radio Times. The BBC WAC has significant value for historical research, not only regarding production practices and the organization of BBC programmes, but also in terms of the broadcaster's relationships with motor sporting organizations and venues. ${ }^{21}$ Although the holdings of the BBC WAC are vast, not least in the papers relating to sport broadcasts, the available records on motorsport are relatively small: seven files directly relating to motorsport between 1947 and 1969 have been referred to, with smaller ad hoc references appearing in the BBC's flagship sports magazine programmes Sportsview and Grandstand over a similar period. We would suggest this is a relatively small collection of papers and, we would argue, rather obscure when compared to 
other aspects of sports programming and information on other television genres held in the BBC WAC.

While this delimits the range of programming analysed, it does serve to emphasise the difficulty the $\mathrm{BBC}$ had in devising an appropriate technological and audio-visual language to effectively cover motorsport at this time. As Garry Whannel has previously noted, much of this challenge emerged as a result of attempts to combine two seemingly irreconcilable production ideologies: that of realism and entertainment. ${ }^{22}$ The BBC WAC does provide evidence of how outside broadcast producers of motorsport attempted to reconcile these ideological elements, meeting the needs to give the viewer a 'grandstand seat' of the action, at the same time providing entertainment through relaying the suspense of competition and 'celebrity' of the drivers. The written archives are therefore of major significance in our attempts to understand how formative forms of television production attempted to bring motorsport to the screen. Specifically, in using the production notes from the written archives we have been keen to look at how the many technical difficulties of broadcasting from motorsport provide evidence of early movements in the 1950's towards the 'televisual', whereby events were organized to suit the needs of the BBC cameras and its transmission.

In using the BBC Genome digital archive, which contains reference to five million BBC broadcasts, six keywords were entered (scrambling, rallycross, hill climb, Formula 1, grand prix and motor racing) for five five-year time periods (1946-1950; 1951-1955; 1956-1960; 1961-1965; 1966-1970) spanning a total of 25 years and covering the immediate and end of the post-war period. ${ }^{23}$ Additionally, and in view of this study's focus, the search was limited to television related documents only. There were some anomalies created in using this BBC Genome search. For example, the keyword search for 'grand prix' constituted a significant amount of entries relating exclusively to horse racing or the Eurovision Song Contest, nothing whatsoever to do with motor sport. In other instances, entries were limited to a simple listing 
of a motorsport with no further description of what this entailed, for example 'motor racing' could appear as a generic item on the BBC Television Saturday afternoon sport programme Grandstand. One further limitation to note is that the programming schedules published did not always correspond to what was broadcast by the $\mathrm{BBC}$ in reality. Outside broadcasts from sport were often victims to the weather, with cancellation of events commonplace. Alternatively, the BBC made late decisions to cover sporting events beyond the listing deadline for the Radio Times. Such broadcasts therefore do not appear in BBC Genome, and may not always be traceable in the written archives either. These limitations aside, the table of broadcasts we have produced is the fullest quantitative account of the BBC's motorsport programming between 1946 and 1970 yet published.

Supplementary qualitative research drew from a series of oral history interviews conducted by one of the authors in a previous study, which has hitherto not been published. ${ }^{24}$ This includes a semi-structured interview with retired BBC motorsport commentator Murray Walker at his home in 2009. Finally, archival and oral history interviews have been further supplemented by autobiographical material written by those involved in the early broadcasts from motorsport. This includes autobiographical material written by Murray Walker, the late BBC motorsport correspondent Raymond Baxter, and newspaper articles and opinion pieces collected in the personal archive of the late Peter Dimmock, former General Manager of BBC Outside Broadcasts. ${ }^{25}$ The experience of being a sports commentator and the human engagement with the practices and institutions of broadcasting are frequently ignored in media histories, which often focus on the ideological and discursive structures of the broadcasts themselves. The biographical analysis provides both valuable insights in terms of individual or organizational behaviour, motives, identity and conditions, as well as providing another context from which to interpret archive material through personal memory and testimony. ${ }^{26}$ 


\section{From World War II onwards: the Emergence of Motorsport in Britain}

Few studies have adopted a historical approach to analyze the relationships between motorsport and television. According to Bill Eastoe, television acted as a major force behind the development of a global motorsport industry from the end of the 1960s as television gradually brought the excitement and danger of racing into people's living rooms ${ }^{27}$. However, what exists of academic research in terms of motorsport is limited and tends to focus largely on the period of when Formula 1 developed itself into its contemporary global mega-sport form. ${ }^{28}$ Bearing this in mind, the emergence of motorsport in BBC programming needs to be understood in relation to a number of developments regarding both the increased popularity of motorsport in Britain and the emergence of early television broadcasting technologies. The rise in popularity of motorsport during the immediate post-war years and which extended throughout the 1950's is correlated to both a high demand for cheap personal mobility and a low-barrier accessibility for the general public. ${ }^{29}$ In spite of nationwide shortages of basic raw materials and rationing, British motorsport flourished on the back of the many surplus World War II airfields that scattered the British countryside. Motor sports such as the 500cc Club (1947-1953) and the 750 Motor Club (1939 - present), were founded on the grass-roots popularity of racing as do-ityourself and self-help networks. ${ }^{30}$ This easy-access club environment gave rise to increased cheap public personal mobility as well as competition and commercial opportunities that saw the erection of the Cooper Car Company, Lola, Cosworth and Colin Chapman's Lotus. Additionally, a number of catastrophic accidents that occurred on the continent during the second half of the 1950s (Le Mans 1955, 83 dead; Monza 1955, lead Lancia driver Alberto Ascari dies; Mille Miglia 1957, 11 dead) led to many of the dominant manufacturers, such as Mercedes, Lancia and Maserati, which had so long outperformed their British competitors, pulling out of racing and effectively opening up the way for British high-profile racing teams such as Jaguar, Aston Martin, Cooper and Lotus to become successful. ${ }^{31}$ Further, this specific post-war era in Britain allowed for British drivers such as Stirling Moss, Mike Hawthorn and 
Jim Clark to emerge into sporting heroes supported by the sporting press and cinema newsreel, which not only sparked a sense of national identity, but also increasingly drew in more audiences to British motorsport. ${ }^{32}$

\section{Motor Sport on Post-War Television}

The BBC's television service began in November 1936 and during its opening month of transmission it screened a film taken of a vintage car rally, 'The Old Crocks Race' from London to Brighton. A year later the $\mathrm{BBC}$ had begun to transmit genuine outside broadcasts, and in October 1938 broadcast its first ever live coverage from motorsport from the International Imperial Race from Crystal Palace in London. ${ }^{33}$ With the exception of a 'Soap Box Derby', also from Crystal Palace, these were the only transmissions of motor racing BBC Television transmitted prior to the suspension of its service in 1939.

Attempts to cover motorsport in earnest began following the resumption of the BBC's television service in 1946. Unlike BBC radio coverage of motorsport such as, for example, the Isle-of-Man TT race which gained huge popularity during the 1930s, television coverage during the immediate post-war years proved far more expensive and technically challenging. Indeed, with television coverage of sport in particular still being in its infancy, transmitting television signals outside the immediate radius of Greater London proved troublesome and "cameras were the size of a shed' and were restricted by cable length up to 100 yards, which rendered coverage of spatially expansive race tracks impossible. ${ }^{34}$ Also, the cost of overcoming these constraints meant coverage of motorsport was simply not as attractive to the $\mathrm{BBC}$ as other sports were. In August 1947, the BBC tentatively experimented with coverage of motorcycling from Brands Hatch in the Kentish countryside by integrating a series of after-race interviews with competitors. BBC producer Philip Dorté drew on a personal contact in the motor racing world, Alan Hess at the Austin Motor Company, to organize the broadcast, and the BBC hired Graham Walker to present the programme and commentate on the racing. Walker, father of Murray 
Walker, had become the BBC's primary motorsport radio commentator during the $1930 \mathrm{~s}$, and like many of his contemporaries was given the opportunity to add his voice to television sports coverage. In a production review, then BBC producer Peter Dimmock noted his disappointment with the content of the programme due to boring racing, and noted that Walker was clearly knowledgeable about motor-cycling, but 'was very much inclined to 'run away' as if on a sound broadcast.' ${ }^{35}$ Dimmock concluded: 'This is I am afraid, yet another instance where the sound OB instruction 'keep talking at all costs' has become firmly established in a commentators mind, and is hard to erase. ${ }^{36}$ Dimmock's comments reflected an emerging set of conventions among television producers of sport that commentary should add to the picture rather than dominate it. The phrase, 'if in doubt, say nowt' emerged within the BBC outside broadcasting department during the immediate post-war period. ${ }^{37}$

Following the initial coverage of racing from Brands Hatch, motorsport broadcasts remained scarce on $\mathrm{BBC}$ Television until 1951 mainly due to the fact that most meetings occurred on Sundays, which ran against the BBC policy of the time to observe a day of rest in terms of live television coverage of sport. The BBC's reluctance to televise motor racing drew criticism from those who championed the sport, in a feature for the weekly magazine TV Mirror Captain W. J. Bentley lamented, 'where motor racing is concerned the TV people have really been very reluctant starters' ${ }^{38}$

Nevertheless, as table 1 substantiates (specifically for the keyword entries Formula 1, Grand Prix and motor racing), the mid-1950s was a period in which television coverage of motorsport rose significantly compared to previous years. There are two principal reasons: first, the Coronation of Queen Elizabeth II in June 1953 induced a massive demand for television sets across Britain with an estimated 8 million sold, which subsequently created a large television audience platform for sport as well. ${ }^{39}$ Indeed, soon after in July 1953, the BBC broadcast its first British Grand Prix: 'Motor racing at Silverstone: the 500 c.c. Race - The fifth R.A.C. British Grand Prix Meeting'. ${ }^{40}$ Second, the Television Act in 1954 ended the BBC's 
monopoly of television broadcasting with the emergence of regional commercial television franchises, ITV, which subsequently instigated a ratings war. One of the BBC's solutions to this sudden competition from commercial television was to extend its coverage of sport to broaden its appeal and audience, which in turn provided the opportunity for motorsport to gain exposure. ${ }^{41}$ Some major additions to the BBC portfolio were the magazine programme Sportsview, the BBC's first regular sports programme in 1954, and Grandstand the BBC's sports-flagship programme introduced in 1958. Both programmes regularly covered motorsport. ${ }^{42}$ In the immediate years following this, Sportsview would broadcast motorsport including coverage of the BBC's first continental motor race, the Monaco Grand Prix, in May 1955.

[Table 1 near here]

'Mud and Unassailable Hills': The BBC's Adoption of Hill Climbs and Scrambling for Television

During the early 1950s, the BBC's motorsport correspondent Raymond Baxter persuaded management of the possibility to include in its television schedules a series of 30-minute motoring non-live programmes called Driving Club which came under the wing of the Outside Broadcast Department. ${ }^{43}$ Following a successful filmed commentary by Baxter on the Royal Automobile Club's (RAC) first international rally, 'the speed hill climb from the famous 'Restand-be-Thankful' hill in the Highlands of Scotland', BBC producer Bill Duncalf wrote to Baxter with a view to devise live coverage of similar hill climb races. 'I believe', wrote Duncalf, 'you have ideas for staging a car trial or exciting hill climb or what not?'. ${ }^{44}$ Under a new collaboration in 1952, Baxter and Duncalf set about devising a new motor racing series specifically designed for television called the BBC Television Trophy Trial:

The idea was to tailor the long-established format of trials driving, which is to see who can complete a series of off-road sections, to the requirements of TV 
broadcasting. We decided to have a series of hill climbs, each divided by five-and ten-point markers, roughly halfway up and at the top. ${ }^{45}$

Either as a group of successive trials under the denominator of 'international trials', or as individual events, hill climbs have been a popular part of motor racing from as early as 1897 (1899 in Britain) and have, due to the delicate ability to race up corkscrew-like courses against the clock, attracted vast numbers of followers from the onset (Flower, 1975). ${ }^{46}$ As such, the hill climb can be defined along the following parameters:

[Cars can tackle] an uphill course one-by-one, with the quickest time dictating the winner. $^{47}$

[Here] race strategy is clear-cut - a 'maximum attack' approach is required from the very first to the last centimeter of the route, as for an athlete running the 100 metres. ${ }^{48}$

Most, if not all, existing hill climbs were still considered too long and unwieldy for television to cover adequately. ${ }^{49}$ Baxter's idea therefore focused on staging time trials amid 'mud and unassailable hills' which were nevertheless 'laid out that maximum coverage could be afforded' in order 'to keep the whole thing in a suitably limited space. ${ }^{50}$ This latter point related to a guiding principle of outside broadcasting of the need to provide maximum action in minimal space. In other words, the challenge to television production was transforming the spatial dimensions of sporting action for the small screen, thereby making the action intelligible for the audience. ${ }^{51}$ The positioning of cameras and the verbal cues provided by commentators are the key production techniques for managing such spatial fragmentation of sporting contests. Applying this principle to motorsport is therefore far more difficult than it is, for example, a boxing match, or events in a sports stadium. ${ }^{52}$ In order to cover motorsport, and considering racing takes place on long race tracks which most often feature a range of bends, undulations and other visual obstructions, this requires a far greater number of cameras and a great deal more editing to create a coherent spatial and temporal overview with any sense of continuity. 
Referring to the challenges and constraints of motor racing broadcasts in his autobiography, Baxter also noted the scaling effect of telescopic lenses which 'reduce the apparent speed of a race car from $160 \mathrm{mph}$ to a sedate crawl' contributing to the 'major problem for those concerned with its presentation on the television screen' ${ }^{53}$ In explaining the rationale for the event to a motorsport journalist, Gregor Grant of Autosport, Baxter made clear his reasoning for the idea: 'The normal Trial is unteleviseable for the simple reason that it goes on too long, has too many competitors, and covers too much ground.' 54

In devising a hill climb for television Baxter turned to a leading rally driver of the period, Godfrey 'Goff' Imhof from the London Motor Club, to recce various hills and select the most suitable course for the trial. ${ }^{55}$ The hill climb course chosen by Baxter and Imhof successfully alleviated many of the technological constraints associated with traditional racetrack coverage including strategic camera placement which allowed for a better overview of the track and a reduction in the number of cameras required as well as more spectacular tracking shots of race cars. ${ }^{56}$ The site, in Wendover State Forest, was kept secret so as to keep the number of on-site spectators to a minimum, and the RAF were employed on site to 'police' the area as stewards. Imhof made arrangements with the drivers, and the producer Duncalf organized their accommodation and hospitality at a hotel near Ayelsbury. Baxter was confident 'that the pull of this caper would be sufficient to get nine of the finest Trials drivers in the country. ${ }^{57}$ The drivers were divided in to three teams: 'the North' represented by Cuth Harrison, Reg Philips and Maurice Wilde; 'the Midlands' represented by Ken Rawlins, Lou Tracey and Bill Sleeman; and 'the South' represented by Wally Waring, Tony Rumfitt and Mike Lawson. ${ }^{58}$ As amateur enthusiasts none of the drivers were paid to compete, but their expenses were covered.

The appeal of the Trials programme for viewers rested on the unfamiliar nature of both the purpose-built cars and their epicurean drivers. A publicity note written by Duncalf proclaimed: 'The cars they will drive are as weird and wonderful as the clothes their intrepid 'pilots' wear - pilot being an appropriate appellation because for much In a letter to the 
manager of the Kings Head Hotel, Duncalf explained the drink preferences of the drivers, with the suggestion: 'that Beer, Whisky and soft drinks be served. This may outrage your chef's finer feelings but the people we are entertaining are somewhat unique I their outlook on life!'59 Duncalf's letter infers the idea of prohibition for drivers prior to racing was anathema to the masculine cult of motorsport of the age. Subsequently, by means of a tailored-for-television motor racing event, the $\mathrm{BBC}$ was able to more effectively 'control' the motor sporting environment of operation to suit its own abilities, and limitations, accordingly. ${ }^{60}$ Producer Bill Duncalf made arrangements for a new BBC trophy to be designed, which used a silver model of an Image Orthocon three turret camera, a design that was later adopted by the $B B C$ Sport Personality of the Year award from 1954. The broadcast cost $£ 240$ of which $£ 36.15$ went on the trophy itself. The $\mathrm{BBC}$ requested the felling of saplings and larger tress that might obstruct the sightlines of their three cameras. ${ }^{61}$ The racing itself was conducted amid fog, which hampered some of the cameras, and the course soon cut up with Duncalf later referring to the racing as 'the battle amidst the mud of Flanders' ${ }^{62}$ 'The South' won the Television Trophy, with Cuth Harrison from 'The North' winning the individual prize, a beer tankard. As a result, the Television Trophy Trial, first broadcast on 15 November 1952, constitutes one of the first attempts by the $\mathrm{BBC}$ to effectively instigate a sporting event for its television cameras. It represents a formative example of television sport, in this case a broadcast from motor racing, purposefully constructing its technological and cultural practices to create a televisual event.

The success of the BBC-led broadcast did not go unnoticed by senior managers in Outside Broadcasting, who in the post-war period had been constantly embattled with sporting authorities over television's access to sporting events. The BBC's Director of Outside Broadcasts, Seymour de Lotbinière, noted the initial Television Trophy broadcast went well. ${ }^{63}$ Amid constructive criticism for improving the scoring system, adding further suspense and adding more technical information on the cars in the running commentary, de Lotbinière observed: 'I think we should explore the possibilities of more BBC promotions of this sort. Not 
only do we thereby bypass promoters who may be worried about television, but we can get the events streamlined to suit television purposes' ${ }^{64}$ These thoughts raised some concern with Cecil McGivern, the BBC's Controller of the Television Service, regarding the $\mathrm{BBC}$ acting as a promotor of sport. First, the Outside Broadcasts department had caused some consternation by awarding a 'BBC Trophy' which had not been cleared with the BBC executive. Second, the $\mathrm{BBC}$ were very sensitive of not upsetting sport promotors, represented by the lobby group the APCS, with the implicit aim to draw attention to the commercial value of television sport, and its member's desire to protect rights of access to spectator sports. ${ }^{65}$ With this in mind, de Lotbinière suggested future events might be better awarded by the organiser of the event rather than the BBC. ${ }^{66}$

From 1952 the BBC expanded its television experience with hill climbs, with two individual events - the Bo'ness Speed Hill Climb: Scotland v. England and the Prescott Hill Climb - and the Television Trophy Trials remaining the main event being promoted. ${ }^{67}$ Unfortunately for the $\mathrm{BBC}$, and despite the best efforts from Baxter, ${ }^{68}$ the 1956 edition was cancelled in 'the national interest' following requests from the British Ministry of Fuel and Power due to the reintroduction of petrol rationing as a result of the Suez fuel crisis ${ }^{69}$. The $B B C$ Television Trophy Car Hill Climb Trial returned in 1957 with the BBC mainly struggling with bad lighting and weather conditions as well as broadcast scheduling issues. ${ }^{70}$

There is little evidence of audience reaction to the hill climb broadcasts in the BBC's written archives, but some indication of their popularity was reported in the specialist magazine The Motor which reported that the 1955 BBC broadcast attracted an audience of 7 million viewers. ${ }^{71}$ Duncalf had reported that the first programme in 1952 had been 'moderately well received by viewers', but it is difficult to fully appreciate how well the broadcasts were received. ${ }^{72}$ Neverthless, while the site of the Trial had been kept secret in 1952 and the BBC did not promote spectators to be on the course, by 1957 the number of spectators had grown to 800 cars parked strategically around the hill climb course, causing a potential hazard for the 
competitors. In 1958 Duncalf reported that the RAF were preparing for 2000 cars to be on the site with permits being issued to manage the parking more appropriately, a programme for the event had been published given away with the Radio Times, and mobile canteen facilities were being introduced to cater for the crowds. ${ }^{73}$

Duncalf promised Goff and Nina Imhof the 1958 Trial would be a 'bumper year' but transformations in the BBC's weekend sports programming threatened to undermine his ebullient mood. The BBC's new flagship Saturday afternoon sports magazine programme Grandstand had been launched in October 1958. The idea of Grandstand was to bring together three or four live outside broadcasts from British sport under one programme organized by studio presentation which dipped in and out of the day's action. On the $22^{\text {nd }}$ November 1958 the Trials had to share the afternoon schedule with horse racing from Worcester and ice hockey from Southampton. Fox attempted to allay Duncalf's fear that the new programme would harm the viewing figures for the Trial, because both the racing and motoring public would be tuning in. ${ }^{74}$ Unlike previous years where the Trial had been broadcast uninterrupted for an hour, the racing on Grandstand was split in to three twenty-minute segments. Duncalf strongly disapproved arguing that the new format did not legitimize the extensive planning and resources the $\mathrm{BBC}$ had invested as a co-promoter of the event. ${ }^{75}$ Moreover, drivers were disappointed with the wait in between each broadcast, so much so that Duncalf feared the best trials drivers would no longer be attracted to compete in the event in future years. ${ }^{76}$ The Television Trophy Trial continued for thirteen editions until 1965, and continued to be integrated in to the schedules of Grandstand. The appeal of hill climbs for motor sport fans, and television, waned as new forms of exciting motor racing emerged on screen in the form of moto-cross (motorcycling scrambles) and Rallycross (a hybrid of racetracks and off-road rallying). 


\section{From Hill Climbs to Rallycross}

With the beginning of the 1960s, the BBC continued to broadcast varying motor races including Formula 1 Grand Prix's and sports car races including the Le Mans 24-Hour Race, where Raymond Baxter reported directly from the circuit. ${ }^{77}$ In spite of this continuation, the aforementioned technological constraints and issues from the 1950s continued to limit televising motorsport by the BBC. ${ }^{78}$ For example, and as Table 1 indicates, broadcasting of hill climbs by the BBC during the second half of the 1960s dwindled. The absence of hill climbs on the $\mathrm{BBC}$ during the second half of the 1960s is, at least in part, due to the creation, of a new winter series, namely Rallycross. ${ }^{79}$ Officially recognized by the Féderation Internationale d'Automobile (FIA) in 1967, Rallycross is a motorsport series in which 'five [originally four] cars line-abreast at the start for short and sharp races of 4 to 6 [short] laps on mixed surfaces, alternating between asphalt and gravel' ${ }^{80}$ Effectively combining the spectacle of rally driving with track racing, the series was first devised by 'pioneering' television producer Robert Reed in 1966, with the specific intent of overcoming many of the existing constraints and issues for televising motorsport, i.e. scheduling, lighting and bad-weather (cancellations):

I got the idea while working on a wet hill climb event in November 1966. [...] There was no point booking another hill climb because it could be cancelled again, so we needed to come up with another event that could fill the gap when other sports were stopped by the weather [...] and leave holes in the TV schedule when cancelled. ${ }^{81}$

For this, Reed adjusted the Lydden Hill (England) track that was visually unobstructed for spectators and which required only four cameras to capture the action, ${ }^{82}$ thus also reducing the issue of temporal fragmentation. ${ }^{83}$ This further enabled commentators to see all competitors on the track at all times and provide a continuous flow of information on all competitors, even after a crash. Created entirely by and for television, Rallycross thus adhered better to the maximum action in minimum space principle than any previous series and as such provided more '[...] 
exciting and spectacular motorsport. ${ }^{94}$ Although having been picked up by ABC TV (ITV) earlier, Rallycross was covered as a 'popular winter series' from 1968 onwards as part of the BBC's Grandstand programme. ${ }^{85}$ Grandstand's exposure subsequently contributed to the series huge rise in popularity through to the rest of the decade and began to make commentator Murray Walker a household name prior to the take off of Formula 1 on television at the end of the 1970 's. ${ }^{86}$

\section{Conclusion: The Post-war Years and Beyond}

By means of an archival approach, this article has shown that due to the significant technical and logistical difficulties associated with televising motorsport, the $\mathrm{BBC}$ experimented with the format of the hill climb by moulding it to fit television's requirements more appropriately which resulted in the creation of the Television Trophy Trial in the 1950's, the adoption of scrambling in the late-1950's and early-1960's, and eventually through Rallycross in the late-1960's and 1970's. The BBC's attempts to create and promote motorsport events for television runs contra to previous suggestions that early televised sport was not televisual. ${ }^{87}$ It would seem that the BBC was not only using motorsport to its own benefit early on, from the early 1950s onwards, but actively creating and representing motorsport as a competitive and dramatic spectacle for television. This, in effect, is in line with Crisell's suggestion that 'television graduated from the modest onlooker to a mighty arbiter whom the world cannot oppose and whose gaze it often courts' ${ }^{88}$ In addition, the BBC's creative intent regarding motorsport was largely a reaction to a sharply increasing popularity for the sport that enjoyed a strong grassroots or club foundation during the immediate post-war period. Subsequently, the adoption of Rallycross by the BBC, following its introduction by producers at ITV from 1967, further suggests the BBC felt it needed to cater to a continually expanding fanbase with further automotive and motorsportoriented programming. While the logistical struggle of broadcasting live motorsport may have been overcome by the 1970 s, the struggle of representing the sport with fast moving cars over a large spatial area remains to the present day. Even with digital technology now exploring the 
realm of virtual reality and augmented reality to complement the many cameras on track, onboard the race cars and in helicopters and drones, the struggle to televise the realism of motorsport for viewers remains.

\section{Funding Details}

Archival research for this article was supported by the AHRC project reference AH/F003528/1

\section{Disclosure Statement}

No potential conflict of interest is reported by the authors

\footnotetext{
${ }^{1}$ Richard Haynes, BBC Sport in Black and White (London: Palgrave, 2016).

${ }^{2}$ John Corner, Television Form and Public Address (London: Edward Arnold, 1995); Author, 2016.

${ }^{3}$ Asa Briggs, The History of Broadcasting in the United Kingdom, vol. 4 of Sound and Vision. (Oxford: Oxford University Press, 1979);Steven Barnett, Games and Sets: The Changing Face of Sport and Television (United Kingdom: British Film Inst, 1990); Gary Whannel, Fields in Vision: Television Sport and Cultural Transformation (London: Routledge, 1992).

${ }^{4}$ Haynes, BBC Sport in Black and White.

${ }^{5}$ Ibid.

${ }^{6}$ Barnett, Games and Sets.

${ }^{7}$ Haynes, BBC Sport in Black and White.

${ }^{8}$ Whannel, Fields in Vision; Briggs, Sound and Vision, 855.

${ }^{9}$ Corner, Television Form and Public Address.

${ }^{10}$ The title of Murray Walker's autobiography draws from one of his more infamous lines "Unless I am very much mistaken.... I AM very much mistaken!". Murray Walker, Unless I'm Very Much Mistaken, (London: HarperCollins, 2002).

${ }^{11}$ Richard Haynes, 'A Pageant of Sound and Vision: Football's Relationship with Television, 1936-60', The International Journal of the History of Sport 15, no 1, (1998): 211-26; Williams, Jack Cricket and Broadcasting (United Kingdom: Manchester University Press, 2011); Kasia Boddy, The Culture of Boxing (London: Reaktion Books, 2009); Clive Everton, Black Farce and Cue Ball Wizards: The inside Story of the Snooker World (Edinburgh: Random House, 2011).

${ }^{12}$ Martin Kelner, Sit Down and Cheer: A History of Sport on TV (London: Bloomsbury publishing, 2012); Haynes, $B B C$ Sport in Black and White.

${ }^{13}$ Nick Henry, Tim Angus, Mark Jenkins and Chris Aylett, Motor Sport Going Global: The Challenges Facing the World's Motorsport Industry (London: Palgrave McMillan, 2013), 1-2.

${ }^{14}$ David Hassan, 'Epilogue: The Evolution of Motor Sport Research', The International Journal of the History of Sport 28, no. 2 (2011), 322; Damion Sturm, 'A Glamorous and High-tech Global Spectacle of Speed: Formula One Motor Racing as Mediated, Global and Corporate Spectacle', in Sports Events, Society and Culture, eds. Katherine Dashper, Thomas Fletcher and Nicola McCullough (London: Routledge, 2014), 68; Henry et al., Motorsport Going Global, 1-2.

${ }^{15}$ Bruce Grant-Braham, 'Formula One, Sponsorship and Television: An Historical Perspective', in Explorations in Motoring History, ed. Bryan J. H. Brown (Oxford: Oxbow Books, 1997), 81-108.

${ }^{16}$ Ehren Pflugfelder, 'Something Less than a Driver: Toward an Understanding of Gendered Bodies in Motorsport', Journal of Sport and Social Issues 33, no. 4 (2009).

${ }^{17}$ David Hassan, 'Prologue: The Cultural Significance and Global Importance of Motor Sport', The International Journal of the History of Sport 28, no. 2 (2011), 187.
} 
${ }^{18}$ Raymond Boyle and Richard Haynes, Power Play: Sport, the Media and Popular Culture: Sport, the Media and Popular Culture (Edinburgh: Edinburgh University Press, 2009).

${ }^{19}$ Gary Crawford, 'Consuming sport: Fans, Sport and Culture.' International Journal of Sports Marketing and Sponsorship 6, no. 2 (2004): 47-62; Whannel, Fields in Vision, 1-3.

${ }^{20}$ John Caughie, Before the Golden Age: Early Television Drama, In: J. Corner (Ed.) Popular Television in Britain: Studies in Cultural History. (London: BFI, 1991), 22-41.

${ }^{21}$ Haynes, BBC Sport in Black and White.

${ }^{22}$ Whannel, Fields in Vision, 92.

${ }^{23}$ BBC Genome, 'Genome Beta Radio Times' https://genome.ch.bbc.co.uk/ (accessed August 2, 2018).

${ }^{24}$ Haynes, BBC Sport in Black and White.

${ }^{25}$ Walker, Unless I'm Very Much Mistaken; Raymond Baxter and Tony Dron, Tales of My Time (London: Grub Street, 2007).

${ }^{26}$ Richard Haynes, Voices Behind the Mic: Sports broadcasters, autobiography, and competing narratives of the past. In: Adler ND, Leydesdorff S (ed.). Tapestry of Memory: Evidence and Testimony in Life-Story Narratives. Memory and Narrative, (New Brunswick: Transaction, 2013) pp. 153-176.

${ }^{27}$ Bill Eastoe, (1994). 'Still in With a Sporting Chance', Accountancy 1215 (1994): 34-37.

${ }^{28}$ Hassan, 'Prologue', 187; Grant-Braham, 'Formula One, Sponsorship and Television'; Henry et al., Motorsport Going Global; Sturm, 'A Glamourous High-tech Spectacle of Speed'; Claire Evans, (2013). 'The Media Representation of Formula One as 'Spectacle': Constructing Sport as a Live Mediatised Event' (PhD diss., Cardiff University, 1991).

${ }^{29}$ Beverly Aston and Mark Williams, Playing to Win: The Success of UK Motorsport Engineering (London: Emphasis, 1996), 9.

${ }^{30}$ Ibid., 11.

${ }^{31}$ Ibid., 14; Jörg Walz, The History of Motorsport (Germany: Delius Klasing Verlag, 2017), 97.

${ }^{32}$ Raymond Flower, Motor Sports : A Pictorial History (Glasgow and London: William Collins Sons \& Co. Ltd, 1975), 144, 150; Walker, Unless I'm Very Much Mistaken.

${ }^{33}$ Radio Times, 30 September 1938. 16.

${ }^{34}$ Walker, Unless I'm Very Much Mistaken, 111; Baxter and Dron, Tales of My Time.

${ }^{35}$ Production notes, Brands Hatch, 31 August 1947, BBC Written Archives Centre (hereafter WAC), T14/168.

${ }^{36}$ Ibid.

${ }^{37}$ See Haynes, BBC Sport in Black and White, 44-67.

${ }^{38}$ Captain W. J. Bentley, 'Let's Have More Speed Thrills', TV Mirror, 1953.

${ }^{39}$ Andrew Crisell, An Introductory History of British Broadcasting (London: Routledge, 2005).

${ }^{40}$ Motor Racing at Silverstone: The 500cc Race, Radio Times, 18 July, 1953.

${ }^{41}$ Boyle and Haynes, Power Play: Sport, The Media and Popular Culture.

${ }^{42}$ Briggs, Sound and Vision: The History of Broadcasting; Author, 2016.

${ }^{43}$ Baxter and Dron, Tales of My Time, 167.

${ }^{44}$ Radio Times, 'RAC First International Rally', 5 June, 1951; Duncalf to Baxter, Sept. 1952, BBC WAC T14/229/1.

${ }^{45}$ Baxter and Dron, Tales of My Time, 207.

${ }^{46}$ Anthony Harding, ed., The Guinness Book of Car Facts and Feats (Middlesex: Guinness Superlatives Limited, 1985).

${ }^{47}$ Motor Sport Association United Kingdom, 'Hill Climb', https://www.msauk.org/The-Sport/Types-of-MotorSport/Hill-Climb (accessed August 2, 2018).

${ }^{48}$ Fèdèration Internationale d'Automobile, 'FIA European Rallycross Championship', https://www.fia.com/events/european-rallycross-championship/season-2018/fia-european-rallycrosschampionship (accessed August 2, 2018).

${ }^{49}$ Details of Programme Requirements, 5 Nov. 1952, BBC WAC T14/229/1.

${ }^{50}$ Baxter to Duncalf, 2 October 1952, BBC WAC T14/229/1.

${ }^{51}$ Whannel, Fields in Vision

52 Ibid., 97.

${ }^{53}$ Baxter, 'Motor Racing', 123.

${ }^{54}$ Baxter to Gregor Grant, 5 November 1952, BBC WAC T14/229/1.

${ }^{55}$ Baxter to Haseman, 14 Oct. 1952, BBC WAC T14/229/1.

${ }^{56}$ Details of Programme Requirements, 5 Nov 1952, BBC WAC T14/229/1.

${ }^{57}$ Baxter to Duncalf, 2 October 1952, BBC WAC T14/229/1.

${ }^{58}$ Baxter to Grant, 5 November 1952, BBC WAC T14/229/1.

${ }^{59}$ Duncalf to manager of the Kings Head Hotel, 30 October 1952, BBC WAC T14/229/1. 
${ }^{60}$ Boyle and Haynes, Power Play: Sport, The Media and Popular Culture.

${ }^{61}$ Duncalf to Forestry Products Research Laboratory, 4 November 1952, BBC WAC T14/229/1.

${ }^{62}$ Duncalf to Imhof, DATE November 1952, BBC WAC T14/229/1.

${ }^{63}$ de Lotbinière to Edgar, Burrell-Davis, Singer and Buchan, 19 Nov. 1952, BBC WAC T14/229/1.; Seymour Joly de Lotbinière, known as 'Lobby' was the BBC's Director of Outside Broadcasts from 1935 to 1939 (Radio and Television) and 1946 to 1952 (Radio and Television). From 1952 until 1955 he concentrated exclusively on outside broadcasting for television and is widely credited with transforming the codes and conventions of radio running commentary for BBC sport during those periods; Richard Haynes, "Lobby' and the Formative Years of Radio Sports Commentary, 1935-1952', Sport in History 29, no 1, (2009): 25-48.

${ }^{64}$ de Lotbinière to Television Controller, 24 Nov 1952, BBC WAC T14/229/1.

${ }^{65}$ de Lotbinière to McGivern, 26 Nov 1952, BBC WAC T14/229/1. For APCS see Haynes, BBC Sport in Black and White, 59-61.

${ }^{66}$ Ibid.

${ }^{67}$ Radio Times, 'Bo'ness Speed Hill Climb: Scotland v. England', 29 June, 1953; Radio Times, 'Prescott Hill Climb', 9 April, 1955; Radio Times, 'Television Trophy: Car Hill Climb Trial', 1 October, 1955.

${ }^{68}$ Baxter to Dimmock, 21 November 1956, BBC WAC T14/229/2.

${ }^{69}$ BBC, 26 November 1956, 'Motorists Panic as Petrol Rations Loom'. Available at http://news.bbc.co.uk/onthisday/hi/dates/stories/november/29/newsid_3247000/3247805.stm

${ }^{70}$ Radio Times, 'BBC Television Trophy Car Hill Climb Trial', 23 November, 1957; Imhoff, 23 November 1957, BBC WAC T14/229/4.

${ }^{71}$ The Motor, 31 October 1956, 586.

${ }^{72}$ Duncalf to Grant, 17 November 1952, BBC WAC T14/229/1.

${ }^{73}$ Duncalf to Richard Bright, 27 October 1958, BBC WAC T14/229/4.

${ }^{74}$ Fox to Duncalf, 24 September 1958, BBC WAC T14/229/4.

${ }^{75}$ Duncalf to Fox, 23 September 1958, BBC WAC T14/229/4; Fox to Duncalf, 24 September 1958, BBC WAC T14/229/4.

${ }^{76}$ Ibid.

${ }^{77}$ Radio Times, 'Motor Racing: Le Mans', 10 June, 1961.

${ }^{78}$ Dan Wright, (2017, 10 February). 'Rallycross 50th anniversary: TV Producer Robert Reed Recalls Sport's History at Lydden Hill', Kent Online, February 10, 2017, http://www.kentonline.co.uk/canterbury/sport/rallycross--how-it-all-120348/ (accessed August 20, 2018).

${ }^{79}$ Radio Times, 'Grandstand', 31 October 1970

${ }^{80}$ Fèdèration Internationale d'Automobile, 'FIA European Hill Climb Championship'.

${ }^{81}$ Kent Online, 10 February 2017, 'Rallycross at 50 ${ }^{\text {th }}$ Anniversary'.

${ }^{82}$ Ibid.

${ }^{83}$ Whannel, Fields in Vision.

${ }^{84}$ Radio Times, 'Grandstand', 17 October, 1970.

${ }^{85}$ Radio Times, 'Grandstand', 31 October 1970; Kent Online, 10 February 2017, 'Rallycross at $50^{\text {th }}$ Anniversary'. ${ }^{86}$ Ibid.

${ }^{87}$ Gary Whannel, 'The Unholy Alliance: Notes on Television and the Remaking of British Sport 1965-85'.

${ }^{88}$ Crisell, An Introductory History of British Broadcasting, 174. 